\title{
SIMULADORES DE CIRCUITO PNEUMÁTICO COMO FERRAMENTA DE ENSINO
}

Fernando Lisboa ${ }^{1}$

Geovane Vieira²

\begin{abstract}
RESUMO
Este artigo tem como objetivo incentivar e orientar os professores de diversas instituições de ensino a utilizar softwares de simulação em aulas de acionamentos pneumáticos e hidráulicos, evidenciando as facilidades em trabalhar e interpretar os circuitos desenvolvidos. Neste estudo, mostra as principais contribuições geradas (com a utilização do software) ao ensino-aprendizagem dos estudantes dos cursos técnicos e superiores, melhorando o aproveitamento e entusiasmo dos mesmos. Através da análise de um circuito eletropneumático desenvolvido com o auxílio de um software de simulação, foram avaliadas as vantagens e desvantagens de trabalhar com simuladores. Os resultados desta análise foram mensurados, por meio da realização de pesquisas de satisfação com alunos do Curso Técnico em Ferramentaria de Moldes (CTFM) 3은 semestre e também com alunos do Curso Técnico em Mecatrônica (CTMT) 4a semestre. Os resultados mostraram que $95 \%$ dos estudantes indicaram melhora na captação do conhecimento com a utilização desta ferramenta, 5 \% indicaram que não houve, ou não foram perceptíveis mudanças com a utilização desta ferramenta. Outro método utilizado para avaliar os resultados deste estudo, foi à realização de uma avaliação prática de um circuito eletropneumático, onde neste foi verificado que houve um incremento de $22 \%$ na média geral do CTFM 3 o semestre e de $35 \%$ na média geral do CTMT 4 o semestre.
\end{abstract}

Palavras-chave: Software. Simuladores. Eletropneumática. Ensino-Aprendizagem.

${ }^{1}$ Especialista, e-mail: fernando.lisboa@sc.senai.br

${ }^{2}$ Mestre, e-mail: geovane.vieira@sc.senai.br 


\section{INTRODUÇÃO}

Com o avanço da tecnologia e o atual crescimento do mercado nacional, a necessidade da busca do conhecimento torna-se inevitável. Diante deste cenário, a utilização de recursos digitais para ajudar os alunos a adquirirem competências necessárias para integrar o mercado de trabalho com mais velocidade e principalmente com mais eficiência, se faz necessário. Muitas vezes, o professor encontra dificuldades de repassar ou transmitir seu conhecimento para o aluno, além de tentar envolver o aluno na aula para que ele absorva e compreenda o tema ou conteúdo dado. Este fato pode estar relacionado a vários fatores, como o cansaço físico e mental dos estudantes, devido a grande carga de informação, na qual são submetidos e a fatores externos como a conciliação de trabalho com estudo.

Uma das alternativas ou estratégia de conseguir a atenção dos alunos e alcançar o objetivo de repassar seu conhecimento é utilizar como ferramenta de ensino, simuladores e softwares que facilitam e possibilitam uma melhor visualização do processo industrial a ser demonstrado e a interação com o aluno.

Em algumas áreas é muito vantajoso o uso de softwares e simuladores, pois reduzem o tempo de ensino, ou seja, o aluno compreende com rapidez, aumentando a eficiência e rendimento em sala de aula. No desenvolvimento e projeto de um equipamento ou dispositivo industrial, por exemplo, onde é necessária a instalação de atuadores pneumáticos e válvulas para o comando, é possível realizar a simulação do circuito e dos componentes que serão utilizados no equipamento e seu funcionamento. Desta forma pode-se verificar e testar o funcionamento do circuito até que esteja de acordo com o projeto proposto.

O presente artigo pretende como objetivo geral aumentar a eficiência do processo de ensino-aprendizagem por meio da utilização de software de simulação nas aulas de acionamentos pneumáticos e hidráulicos. E os objetivos específicos, são eles: identificar as vantagem e desvantagens de trabalhar com simuladores; interpretar circuito eletropneumático desenvolvido no software; mostrar como funciona o software e alguns comandos; apresentar pesquisas com os estudantes.

\section{PRINCIPAIS DIFICULDADES NO ENSINO-APRENDIZAGEM}

Conforme Diaz Bordenave e Pereira (1977), as deficiências encontradas no processo de ensino-aprendizagem estão relacionadas a vários aspectos relacionados abaixo:

a) o professor;

b) os programas de estudo; 
c) os métodos, instalações e materiais de ensino;

d) os alunos;

e) as formas de avaliação da aprendizagem;

f) as condições institucionais que afetam o ensino.

Essas deficiências encontra-se em quase todas as instituições de ensino, mas talvez com intensidades diferentes. Outro ponto de dificuldade é a falta de bancadas didáticas, sendo que algumas instituições não tem condições de aquisição, para realizar uma aula prática em laboratório de pneumática.

Levando em conta a dificuldade de aquisição de bancadas em número capaz de atender a demanda, devido ao elevado custo destas, a simulação com recursos computacionais tem sido utilizada e seu emprego tem aumentado consideravelmente, dispondo o mercado de diversos modelos como PneuSim, HidrauSim, FluidSim, Automation Studio, dentre outros, para utilização em simulações e/ou para interligações com os equipamentos atuadores, minimizando o custo de aquisição de diversos equipamentos, e otimizando o processo de ensino-aprendizagem. (FESTO, 2001 apud PEQUENO, 2004).

\subsection{Os métodos e ferramentas de ensino}

O método e as ferramentas de ensino utilizadas em sala de aula é um dos principais fatores que afetam a aprendizagem dos estudantes. Em muitos casos, segundo Diaz Bordenave e Pereira (1977) os estudantes ficam descontentes com muitos dos métodos utilizados em sala de aula.

\footnotetext{
Unanimemente os participantes dos cursos acusam um emprego excessivo, quase exclusivo, da preleção ou aula expositiva, com baixíssima participação dos alunos. Denunciam também um número insuficiente de aulas práticas e o escasso e deficiente uso de recursos audiovisuais. Mencionam diversos casos de emprego inadequado dos recursos visuais. Assim, não é raro ver-se utilizar o álbum seriado como roteiro de aula, com páginas saturadas de letreiros. (DIAZ BORDENAVE E PEREIRA, 1977, p. 17).
}

De acordo com Petitto (2003) o computador pode se tornar um instrumento muito valioso no processo de ensino-aprendizagem e um bom aliado na construção do conhecimento. Com o auxilio do computador os professores têm uma ferramenta que é fundamental para ajudar o aluno nos dias de hoje, mas é importante ressaltar que o uso do computador deva acontecer de maneira correta, a fim de que o aluno construa uma interpretação própria, crie um raciocínio lógico, com fundamentos e informações sólidas, organizando-as para desenvolver algum conhecimento. 
Para Diaz Bordenave e Pereira (1977), os professores precisam fazer uma reflexão profunda de como é o seu método de ensino e trabalho, buscando colocar em prática novas estratégias, inovando com tecnologia e ferramentas eficientes, para melhorar a qualidade da aprendizagem.

\subsection{Alternativas que auxiliam o processo de ensino-aprendizagem}

Uma das alternativas de melhorar o processo de ensino e aprendizagem nas aulas de pneumática e hidráulica é o uso de software de simulação, que tem como vantagem: representações gráficas que demonstram formas construtivas bem próximas da realidade, sendo 2D ou 3D; simulações de movimentos que realmente facilitam a compreensão de funcionamento dos componentes, além de sons e efeitos. Outra vantagem é a rapidez de alteração dos projetos desenvolvidos, e facilidade de interpretação dos circuitos pneumáticos e hidráulicos, com a ajuda de cores padronizadas para auxiliar.

Na figura 1, vemos o exemplo de um circuito eletropneumático desenvolvido no software de simulação. Importante ressaltar que o circuito é básico e foi criado somente como exemplo para estudo deste artigo, além de que o software em si, foi desenvolvido para ser utilizado didaticamente e não profissionalmente em uma empresa como ferramenta de projeto.

Figura 1: Circuito eletropneumático em repouso

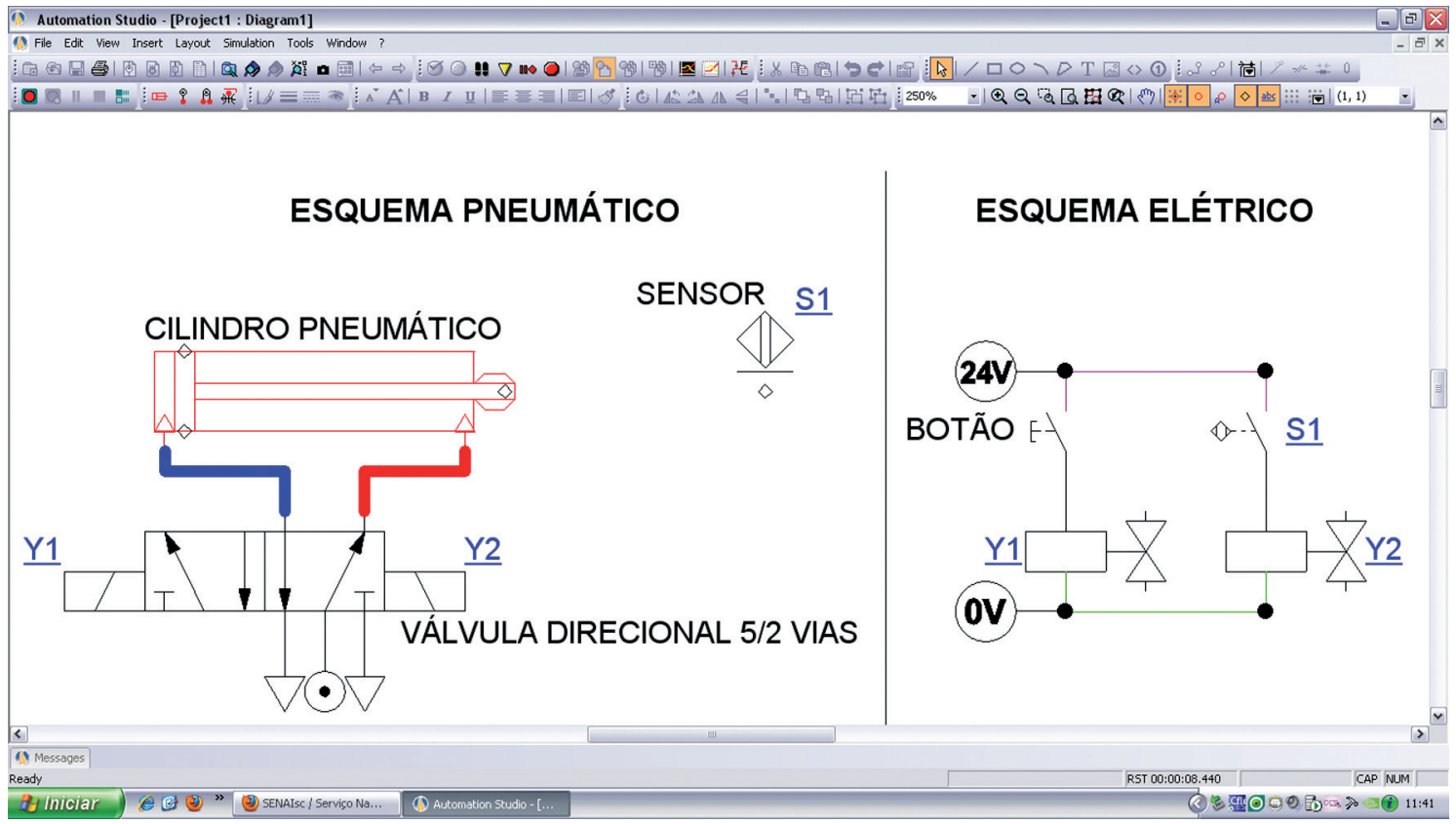

Fonte: Dos autores 
Com o circuito em modo de simulação mostrado na Figura 1, é possível perceber no esquema pneumático que há duas linhas de cores vermelha e azul, que significam linha de pressão e retorno, respectivamente. Essas cores é uma das vantagens que ajudam muito na interpretação do circuito, pois são elas responsáveis pelo movimento do cilindro pneumático. Então se pode compreender que o cilindro pneumático está na posição: recuado e pressurizado.

No esquema elétrico da Figura 2, vemos o momento em que o botão pulsante de contato aberto foi pressionado ficando com cor rosa, indicando a passagem de corrente elétrica até a solenóide $\mathrm{Y} 1$, energizando-a e acionando a válvula ao mesmo tempo. Neste momento a solenóide passou para cor verde, sinalizando que está ligada. No esquema pneumático, consequentemente, a válvula direcional $5 / 2$ vias faz a troca de posição, liberando passagem de ar para a parte traseira do cilindro pneumático, fazendo-o avançar. Nas linhas tracejadas em vermelho, também é possível notar o fluxo de ar, representado pelos vértices dos triângulos.

Figura 2: Botão pressionado

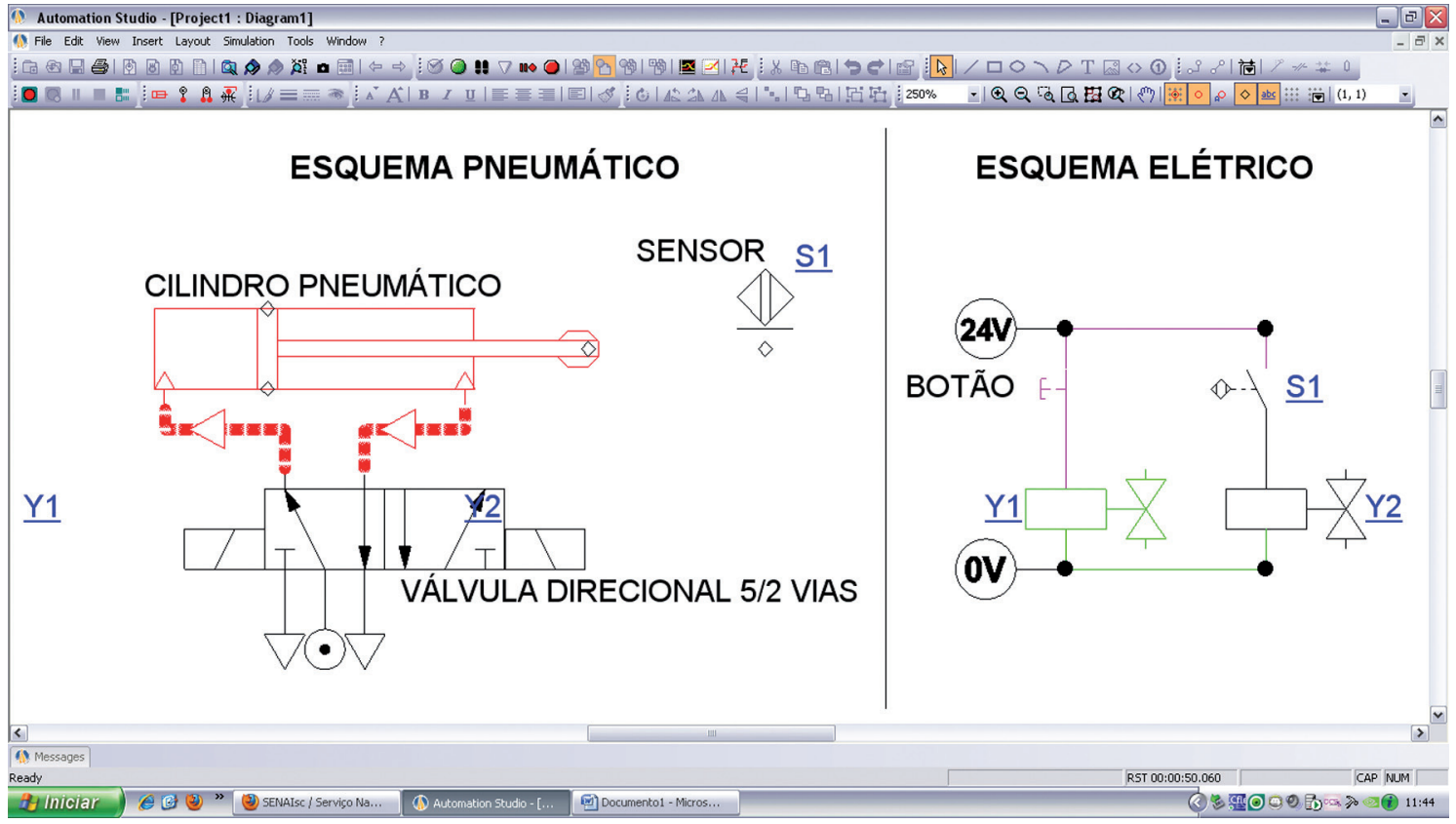

Fonte: Dos autores

Dando continuidade no avanço do cilindro pneumático, ele irá até o seu curso final, acionando o sensor S1. Como se pode observar a Figura 3, o contato do sensor se fecha, conduzindo corrente elétrica indicado pela cor rosa e liga a solenóide Y2 que passa a ficar de cor verde, que simboliza, energizada. 
Figura 3: Cilindro avançado

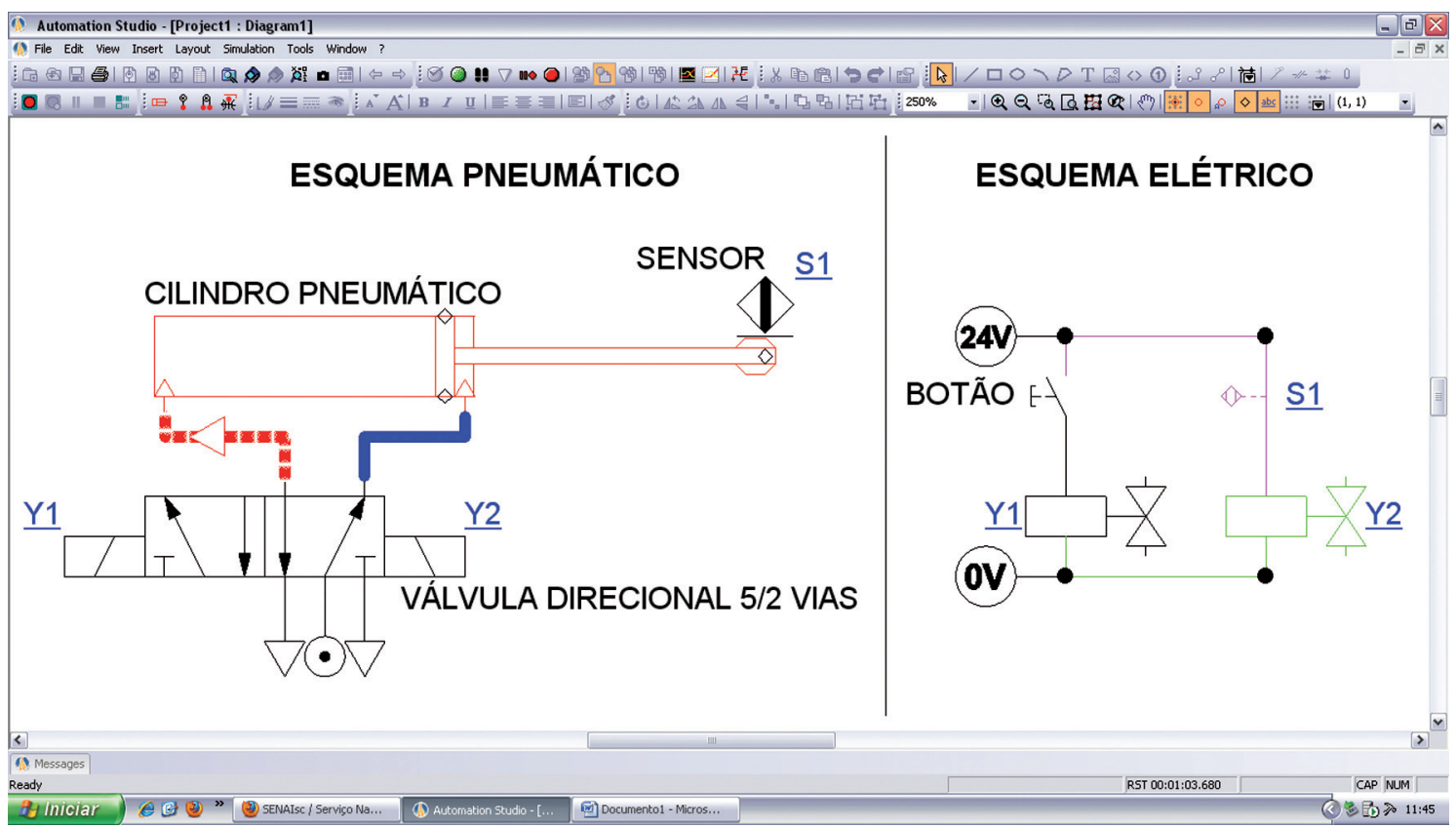

Fonte: Dos autores

Com a energização do solenóide $\mathrm{Y} 2$, a válvula direcional retorna para a posição de repouso, liberando ar para a parte dianteira do cilindro fazendo-o recuar.

Outra vantagem que o software disponibiliza é a visualização interna dos componentes utilizados. Desse modo se torna fácil a compreensão do funcionamento dos componentes, consequentemente, facilita também a interpretação dos circuitos desenvolvidos. $\mathrm{Na}$ Figura 4, observa-se a vista interna do cilindro pneumático de dupla ação. Percebemos que a haste do cilindro está unida junto ao êmbolo através de uma porca sextavada e que também as câmaras dianteira e traseira estão isoladas pela vedação de cor preta, alojadas no êmbolo. 
Figura 4: Animação com vista interna

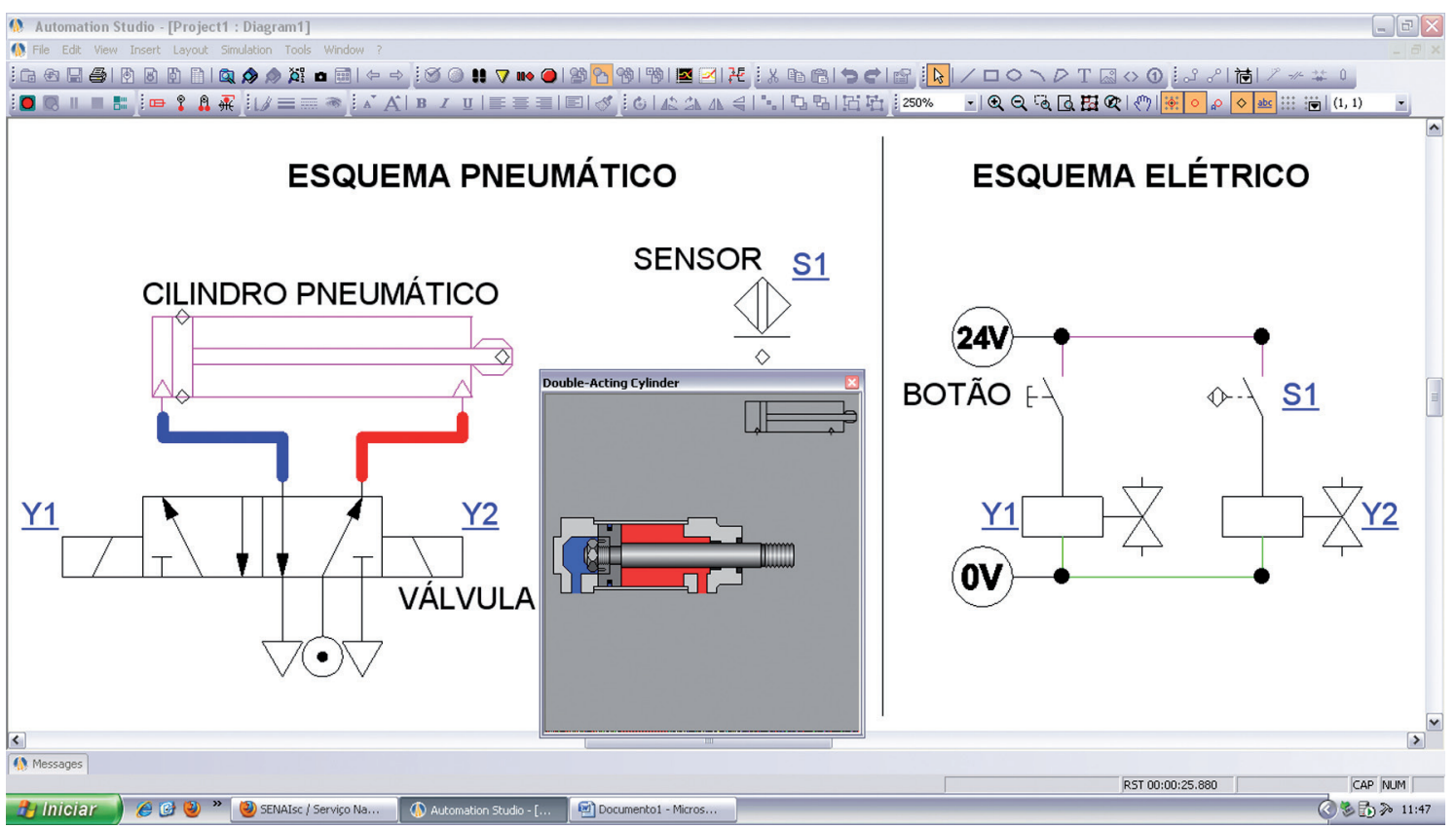

Fonte: Dos autores

Conforme ilustrado na Figura 4, as possibilidades de visualização interna dos componentes facilitam na interpretação do principio de funcionamento dos mesmos.

\subsection{Resultados e discussões}

Os resultados deste artigo foram mensurados por meio da realização de pesquisas de satisfação com alunos do Curso Técnico em Ferramentaria de Moldes (CTFM) 3으 semestre e também com alunos do Curso Técnico em Mecatrônica (CTMT) 4osemestre.

Foram desenvolvidos questionários e avaliações que buscam verificar se os estudantes adquiriram as competências necessárias sobre o tema. Estes resultados foram compilados e demonstrados no Quadro 1. 
Quadro 1: Avaliação de satisfação

\begin{tabular}{|c|c|c|c|c|c|c|c|}
\hline \multicolumn{8}{|c|}{ Avaliação do grau de satisfação dos estudantes da utilização de ferramentas de simulação } \\
\hline \multicolumn{4}{|l|}{ CTFM } & \multicolumn{4}{|l|}{ СTMT } \\
\hline População & Satisfeito & Insatisfeito & $\begin{array}{l}\text { Não res- } \\
\text { ponderam }\end{array}$ & População & Satisfeito & Insatisfeito & $\begin{array}{l}\text { Não } \\
\text { respon- } \\
\text { deram }\end{array}$ \\
\hline 30 & 27 & 0 & 3 & 44 & 42 & 0 & 2 \\
\hline $100 \%$ & $90,00 \%$ & $0,00 \%$ & $10,00 \%$ & $100 \%$ & $95,45 \%$ & $0,00 \%$ & $4,55 \%$ \\
\hline
\end{tabular}

Fonte: Dos autores

Os resultados mostraram que $90 \%$ dos estudantes do CTFM indicaram melhora na captação do conhecimento com a utilização desta ferramenta, $10 \%$ indicaram que as mudanças não foram perceptíveis com a utilização desta ferramenta ou não responderam a pesquisa. Pode se perceber que nenhum estudante avaliou de forma negativa a utilização do software de simulação.

Os estudantes do CTMT também indicaram melhora na captação do conhecimento com a utilização desta ferramenta. O quadro 1 mostra que $95,45 \%$ dos entrevistados se consideram satisfeitos e que esta ferramenta ajudou de forma considerável a captação dos conhecimentos. Outros 4,55 \% dos entrevistados não perceberam mudanças ou não foram perceptíveis após a utilização desta ferramenta. Pode se perceber que nenhum estudante avaliou de forma negativa a utilização do software de simulação.

Após a realização de uma avaliação prática de um circuito eletropneumático, verificouse que houve um incremento de 22 \% na média geral do CTFM 3 semestre e de $35 \%$ na média geral do CTMT 4 ㅇ semestre. $O$ desenvolvimento das atividades práticas sem a utilização da ferramenta de simulação gera nos estudantes muitas dúvidas e muitas vezes, medo dos resultados em virtude da falta de confiança no aprendizado. Com a utilização desta ferramenta, mais de $90 \%$ das atividades práticas conseguiram ser concluídas sem a ajuda do professor, bem como de outros estudantes. Este fato está relacionado à realização das simulações, onde com a demonstração clara dos componentes a serem utilizados e os testes de lógica realizados, pode-se avaliar os possíveis defeitos.

\section{CONCLUSÃO}

Desenvolvendo essa pesquisa, foi possível verificar que a utilização do software de simulação, auxilia aos professores a desenvolverem a construção do conhecimento nas disciplinas de Hidráulica e Pneumática. Os resultados das pesquisas de satisfação 
dos estudantes demonstraram que foram importantes para o desenvolvimento do conhecimento. As práticas de ensino e aprendizagem foram melhoradas, em aproximadamente $90 \%$ dos estudantes.

O professor encontrou mais facilidade de transmitir seu conhecimento para os estudantes, além de envolvê-los nas atividades de sala de aula para que absorvessem e compreendessem o tema ou conteúdo. Este fato está relacionado a vários fatores, um deles, a diminuição do cansaço físico e mental. Com a utilização do software de simulação, os estudantes foram mais estimulados a resolver os problemas de forma rápida, eficaz e com conhecimento do tema abordado.

Verificou-se que a interação e contextualização do cenário a ser aplicado às diversas atividades propostas resultaram em maior êxito, pois possibilitaram uma melhor visualização do processo industrial a ser demonstrado.

\title{
PNEUMATIC CIRCUIT SIMULATORS AS A TEACHING TOOL
}

\begin{abstract}
This article aims to encourage and guide teachers in various educational institutions to use the simulation software classes in pneumatic and hydraulic actuators, showing the facilities to work and interpret the developed circuits. This study shows the main contributions generated (using the software) to the teaching and learning of students of technical courses and higher, improving the use and enthusiasm of the students themselves. Through the analysis of an electropneumatic circuit developed with the help of software the advantages and disadvantages of working with simulators were evaluated. The results of this analysis were evaluated by carrying out satisfaction surveys with students from Technician Tooling Mould (CTFM) 3rd semester and also with students of the Technical Course in Mechatronics (CTMT) 4th semester. The results showed that $95 \%$ of students indicated improvement in the capture of the knowledge with using this tool, 5\% showed no, or not noticeable changes using this tool. Another method used to evaluate the results of this study was to perform a practical evaluation of an electro-pneumatic circuit, where it has been found that there was a grade increase of 22\% average overall CTFM 3rd semester and 35\% average overall CTMT 4 semester.
\end{abstract}

Keywords: Software. Simulators. Electro-pneumatic. Teaching and Learning. 


\section{REFERÊNCIAS}

DÍAZ BORDENAVE, Juan E.; PEREIRA, Adair Martins. Estratégias de ensino-aprendizagem. 27. ed. Petrópolis, RJ: Vozes, c1977.

PEQUENO, Doroteu Afonso Coelho. SIMULA: um software educativo de simulação de circuitos pneumáticos com aplicações de lógica Fuzzi. 2004. 140 f. Dissertação (Mestrado Integrado Profissionalizante em Computação)-Universidade Estadual do Ceará, Fortaleza, 2004.

PETITTO, Sonia. Projetos de trabalho em Informática: desenvolvendo Competências. Campinas: Papirus, 2003.

\section{SOBRE OS AUTORES}

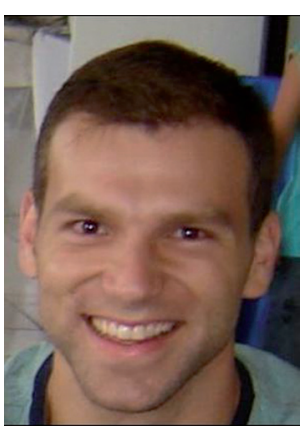

Pós Graduado em Engenharia de Manutenção Industrial (SENAI - Joinville/SC). Graduado em Processos Industriais - Habilitação em Eletromecânica - (SENAI - Joinville/SC). Atualmente é docente no SENAI - Joinville/SC - nos curso Técnico de Automação Industrial, Ferramentaria de Moldes e Mecatrônica. Atua também como orientador de TCC no Curso Superior em Tecnologia de Mecatrônica, além de, exercer a função de mecânico industrial na Empresa Mexichem Brasil.

Fernando Lisboa

\begin{tabular}{|l|l|}
\hline & $\begin{array}{l}\text { Mestre em Engenharia de Processos, UNIVILLE, Especialista em Engenharia de } \\
\text { Automação, SOCIESC, Tecnólogo em Processos Industriais com Habilitação em } \\
\text { eletromecânica, UNIVILLE/SENAI. } \\
\text { Professor Especialista de Ensino do Núcleo de Automação e Mecatrônica do } \\
\text { SENAl, Joinville. Atualmente leciona diversas disciplinas para os Cursos de Pós } \\
\text { Graduação e Superiores de Tecnologia em Mecatrônica Industrial, Redes de } \\
\text { Computadores e Fabricação Mecânica e também para os cursos técnicos em } \\
\text { Automação Industrial e Mecatrônica. } \\
\text { Há mais de } 10 \text { anos, exerce a função Especialista de Manutenção na Empresa } \\
\text { Mexichem Brasil, desenvolvendo e gerenciando diversos projetos de melhorias } \\
\text { de processos de Extrusão, Injeção e Sopro. Atua fortemente em projetos de } \\
\text { adequação de equipamentos as normas NR 10 e NR12; } \\
\text { Realiza consultorias em empresas metal mecânica, automação e de processos } \\
\text { da região norte de Santa Catarina, com ênfase em instrumentação e controle de } \\
\text { processos automatizados, adequação às normas NR 10 e NR12. }\end{array}$ \\
\hline Geovane Vieira
\end{tabular}

